\title{
Life Cycle Sustainability Analysis for Circular Economy
}

\author{
Vanesa G. Lo Iacono Ferreira ${ }^{1}$, Juan Ignacio Torregrosa López ${ }^{1}$ \\ ${ }^{1}$ Department of Chemical and Nuclear Engineering, Higher Polytechnic School of Alcoi \\ (UPV), Spain.
}

\begin{abstract}
A Life-Cycle Sustainability Analysis is a complex assessment that requires time, expertise and quality data. Decision-making boards of industries required live data to manage their business. Although planned changes can be made pursuing innovation and sustainability within a wide timeframe, daily decisions are often driven just by economic indicators. However, many industries are already implementing systems, simple or complex, that allow them to obtain some environmental or social information related to their activities aware that not only economic value fosters the circular economy that our planet needs.
\end{abstract}

Key performance indicators are excellent information suppliers that can be defined either in the economic, social or environmental areas of a sustainable analysis. Willing to develop a methodology easy to apply in existing decisionmaking panels that incorporate social and environmental indicators to fill the gap of sustainability analysis, this research group is exploring new protocols and procedures to define customized key performance indicators. The inclusion of key performance indicators based on Life Cycle Assessment in existing management panels will serve as a tool to make the commitment of our European industries with a circular economy come true.

Keywords: sustainability life cycle assessment. 


\section{Introduction}

The European Commission is promoting projects with a high level of readiness to make the needed transition of organizations (including industries) into the Circular Economy easier and faster. A recent topic under the Nantoechonologues, Advanced Materials, Biotechnology, and Advanced Manufacturing and Processing funding program has been released. This call is looking to develop methodologies to incorporate social and economic indicators in sustainability evaluation with a high level of readiness.

This article draws the framework of a project proposal seeking to develop a quantitative approach that allows assessment of the sustainability multicriteria trade-off of circularity dynamically in real cases (cradle to cradle). The goal os to facilitate the incorporation of exiting products harmonized approach with a public demonstration where it is imperative to work with industrial associations and clusters to engage with industry, SMEs, consumers, standardization bodies and the rest of stakeholders.

Before presenting the methodology proposal, the three main concepts fundamental pillars of these project are shortly described.

\subsection{Life Cycle Sustainability Assessment}

Life Cycle Assessment (LCA) is a tool to assess the environmental impact of products, services or organizations over all their life cycles. It is well documented and widely applied following recognized standards (International Organization for Standardization, 2006a; 2006b). LCA is one of the most accepted tools for the study and measurement of environmental impacts related to products and services and, since de last 5 years, also to organizations. LCA gives detailed information regarding all the environmental impacts of the product that helps both the understanding of the environmental performance and comparison between different products. It is essential when applying eco-design. Choosing the best materials implies having enough information regarding its economic value, technical and environmental performance. However, an LCA requires a significant amount of resources and time that makes it difficult to implement in a decision-making process at an organizational management level (Lo-Iacono-Ferreira et al., 2016).

Although environmental impacts are relevant, there are two other aspects essential for sustainability. The integration of social and economic benefits with environmental burdens results in a true Life Cycle Sustainability Assessment. 


\subsection{Key Performance Indicators}

The main tool that management boards use are the Key Performance Indicators (KPI). These indicators are, traditionally, economic and financial indicators related to critical factors(Kerzner, 2011; Parmenter, 2015). KPIs are defined by:

- finding the organization's operational critical success factors

- determining measures that will work in the organization

- getting the measures to drive performance

Identifying the relevant values for an organization is the first step in any KPI definition process. The definition and implementation in operational and management boards of KPI environmentally-related are not frequent. However, more and more complex organizations are investing in projects to define environmental and social KPIs in order to apply them as management and operational tools for everyday decision-making (Lo-Iacono-Ferreira et al., 2018).

There are different techniques where it can be highlighted the exploratory factor analysis and the structural equation modeling. Recognized authors as Vachon and Klassen (2006, 2008), Govindan et al. (2015) and Nejati and Nejati (2013) have explored statistical methodologies as the exploratory factor analysis to identify relevant variables. It is a frequent complementary tool of sustainability analysis of supply chains, certification processes and sustainability factors of universities. Structural equation modeling has been used in environmental performance assessment of small and medium-size manufacturers (Hussey and Eagan, 2007).

\subsection{Circular Economy}

Circular Economy is the framework needed to ensure sustainability. It is a hot topic in the industry and the R+D+i environments (Urbinati, A. et al., 2017). It is based on three principles:

1. design out waste and pollution

2. keep products and materials in use

3. regenerate natural systems

Re-thinking and re-designing the processes used in production and services is the key to preserve materials and energy as designing new products and materials with this vision. It is a new approach where the concept closed-loop economy and cradle-to-cradle have full attention (McDonough and Braungart, 2002; Murray et al., 2017). To achieve the efficient loop of products (maintaining them as long as possible as useful material)

Linder and Williander (2015), Vermeulen (2015) and Crainer (2013) have already explored the Circular Economy as a paradigma that organizations can implement form a business 
model point of view. The traditional life cycle needs to change to something new and tridimensional (Figure 1), where it is no longer a circle but a sphere with different paths that a product or material can take depending on its characteristics and the needs of the system to close the loop (Korhonen et al., 2018).

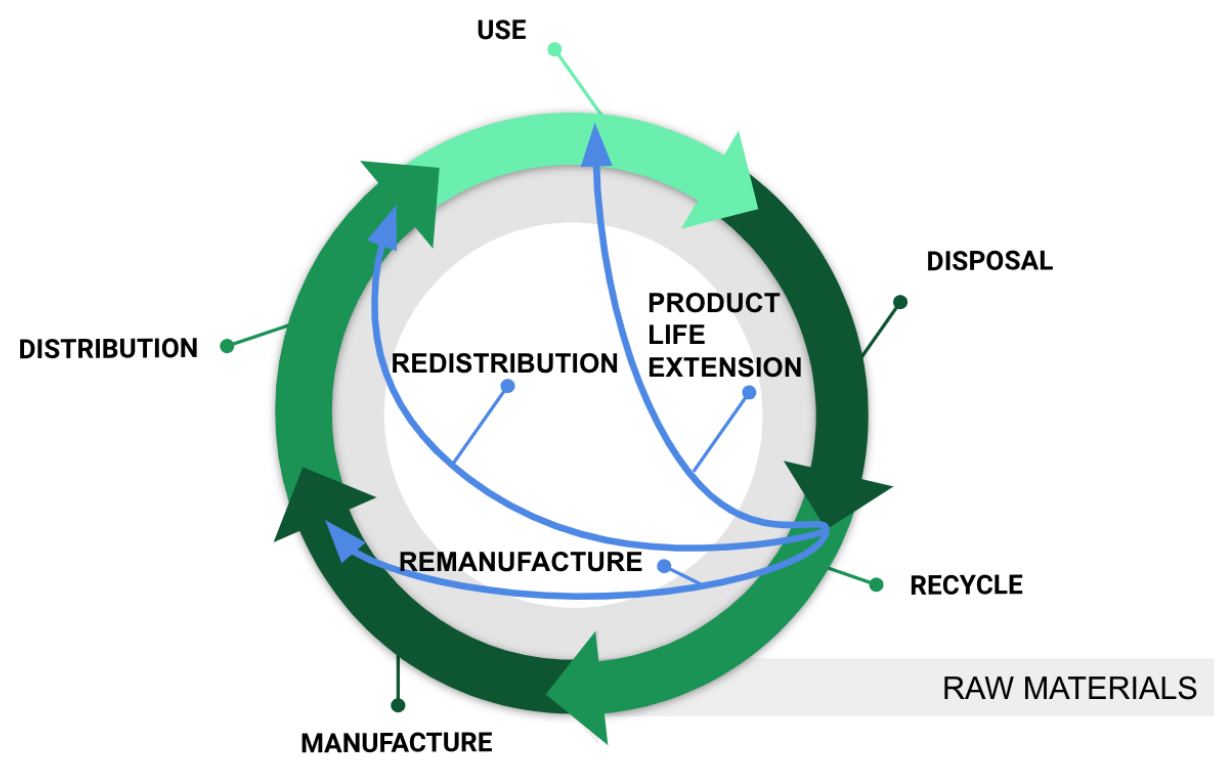

Figure 1. Spheric life cycle.

\section{Methodology proposal}

The context of an organization is complex; different stakeholders are involved and external and internal influences required attention. To ensure a successful result for the project, the methodology developed by the European Commission (2010) plan-do-check-act (PDCA) methodology is proposed (Figure 2). The context will be first defined followed bu the goals and scope. Stakeholders, internal and external influences will be analyzed to identify risks and opportunities. Then, the wheel will start moving from plan to do, checking to verify results and acting to improve the performance of the tool developed to continue with the circle. 


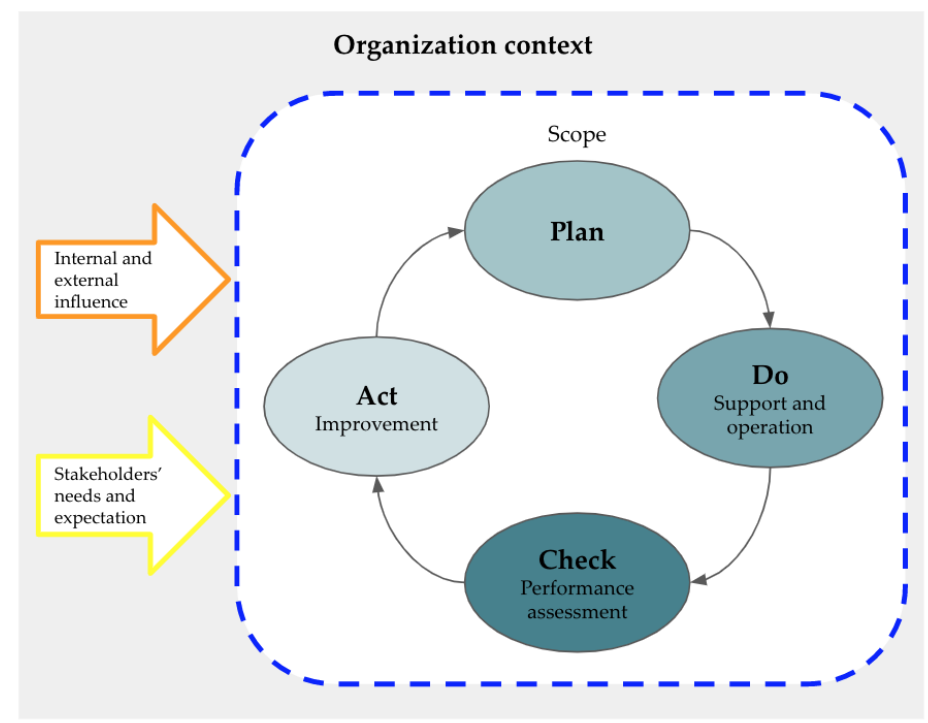

Figure 2. PDCA

To design the tool based on KPIs a proven methodology in complex organizations (LoIacono-Ferreira et al., 2018) is proposed. The methodology is based on a continuous improvement system where stakeholders participants in the first stages and the system is validated in situ with real data (Figure 3).

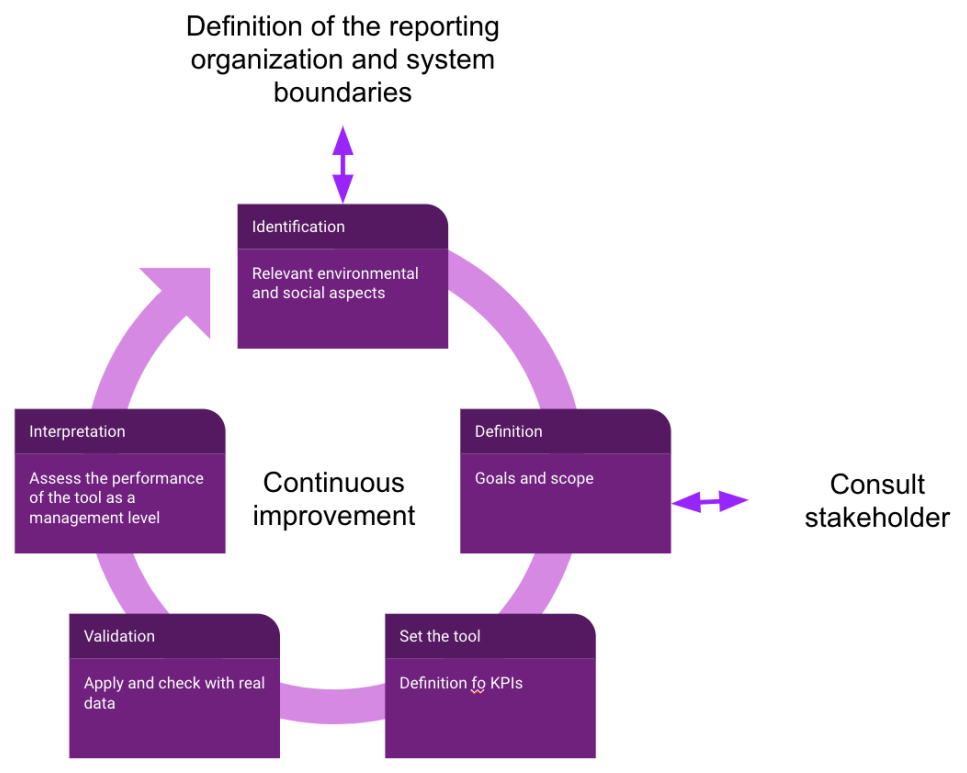

Figure 3. Continuous improvement methods. 


\section{Our project, conclusions, and goals}

The European Commission and many of the European countries are promoting the paradigma change to drive Circular Economy. An early-stage sustainability evaluation tool that allows increasing the consistency across sectors through value chains is needed. Decision-makers need to be better informed to design and develop future products and processes through improving the visualization and communication of potential sustainability trade-offs with stakeholders.

Through this project, new business opportunities will be highlighted and the competitiveness of European industries will be increased; SMEs will be able to access new support in the transition to the circular and sustainable economy.

We have wide experience in sustainability assessment with experimental proof of new concepts and validation in relevant environments. Life Cycle Assessment and Key Performance Indicators in complex organizations and city management are our specialties. We have the opportunity to improve product investment toward the Circular Economy by forming a consortium of researchers, technology developers, and organizations that provide real data allowing the definition KPIs in the management system of industries.

\section{References}

Crainer, S., (2013) Squaring the circle. Bus. Strategy Rev. 24 (4), 13-19. https://doi.org/10.1111/j.1467-8616.2013.00988.x

European Commission - Joint Research Centre - Institute for Environment and Sustainability: International Reference Life Cycle Data System (ILCD) Handbook - General guide for Life Cycle Assessment - Detailed guidance. First edition March 2010. EUR 24708 EN. Luxembourg. Publications Office of the European Union; 2010

Govindan, k., Rajendran, S., Sarkis, J., Murugesan, P., (2015) Multi criteria decision making aproaches from Green supplier evaluation and selection: a literature review. J. Clean. Prod. 98, 66-83. https://doi.org/10.1016/j.jclepro.2013.06.046.

Hussey, D.M., Eagan, P.D., (2007) Using structural equation modeling to test environmental performance in small and medium-size manufacturers: cab SEM helps SMEs? J. Clean. Prod. 15 (4), 303-312. https://doi.org/10.1016/j.jclepro.2005.12.002.

International Organization for Standardization (2006a) Environmental Management Life Cycle Assessment e Principles and Framework. ISO 14040:2006.

International Organization for Standardization (2006b) Environmental Management Life Cycle Assessment e Requirements and Guidelines. ISO 14044:2006(E).

Kerzner, H.R., (2011) Project Management Metrics, KPIs, and Dashboards: a Guide to Measuring and Monitoring Project Performance. John Wiley \& Sons. https://doi.org/10.1002/9781118086254 
Korhonen, J., Nuur, C., Feldmann, A., Birkie, S.E. (2018) Circular economy as an essentially $\begin{array}{lllll}\text { contested concept. J. Clean. Prod. 175, 544-552 } & \end{array}$ https://doi.org/10.1016/j.jclepro.2017.12.111

Linder, M., Williander, M., (2015) Circular business model innovation: inherent uncertainties. Bus. Strategy Environ. 26 (2), 182-196. https://doi.org/10.1002/bse.1906

Lo-Iacono-Ferreira, V.G., Capuz-Rizo, S.F., Torregrosa-López, J.I. (2018) Key Performance Indicators to optimize the environmental performance of Higher Education Institutions with environmental management system - A case study of Universitat Politècnica de València. Journal of Cleaner Production, 178, 846-865. https://doi.org/10.1016/j.jclepro.2017.12.184

Lo-Iacono-Ferreira, V.G., Torregrosa-López, J.I., Capuz-Rizo, S.F. (2016) Use of Life Cycle Assessment methodology in the analysis of Ecological Footprint Assessment results to evaluate the environmental performance of universities. Journal of Cleaner Production, 133, 43-53. https://doi.org/10.1016/j.jclepro.2016.05.046

McDonough, W., Braungart, M., (2002) Cradle to Cradle: Remaking the Way We Make Things. New York: North Point.

Murray, A., Skene, K., Haynes, K., (2017) The circular economy: an interdisciplinary exploration of the concept and application in a global context. J. Bus. Ethics 140 (3), 369380. https://doi.org/10.1007\%2Fs10551-015-2693-2

Nejati, M., Nejati, M., (2013) Assessment of sustainable university factors from perspective of university students. J. Clean. Prod. 48, 101e107. https://doi.org/10.1016/j.jclepro.2012.09.006.

Parmenter, D., (2015) Key Performance Indicators: Developing, Implementing, and Using Winning KPIs. Jhon Wiles \& Sons.

Urbinati, A., Chiaroni, D., Chiesa, V., (2017) Towards a new taxonomy of circular economy business models. J. Clean. Prod. 168, 487-498. https://doi.org/10.1016/j.jclepro.2017.09.047

Vachon, S., Klassen, R.D., (2006) Green project partnership in the supply chain: the case of the package printing industry. J. Clean. Prod. 14, 661-671. https://doi.org/10.1016/j.jclepro.2005.07.014.

Vachon, S., Mao, Z., (2008) Linking supply chain strength to sustainable development:a country-level analysis. J. Clean. Prod. 1552-1560. https://doi.org/10.1016/j.jclepro.2008.04.012.

Vermeulen, W.J., (2015) Self-governance for sustainable global supply chains: can it deliver the impacts needed? Bus. Strategy Environ. 24 (2), 73-85. https://doi.org/10.1002/bse.1804 